\title{
Simulated training of a laparoscopic vesicourethral anastomosis ${ }^{1}$
}

Eudes Fontenele Moraes Pinheiro', Márcio Alencar Barreira", Luiz Gonzaga de Moura Junior'I', Charles Jean Gomes de Mesquitaiv, Rômulo Augusto da Silveirav

'MD, Instituto Dr. José Frota, Fortaleza-CE, Brazil. Conception and design of the study; technical procedures; acquisition, interpretation and analysis of data; manuscript preparation and writing.

"MD, Instituto Dr. José Frota, Fortaleza-CE, Brazil. Manuscript preparation, critical revision.

I'PhD, Assistant Professor, Professional Master's degree, Program in Minimally Invasive Technology and Simulation in Health, Centro Universitário Christus (UNICHRISTUS), Fortaleza-CE, Brazil. Conception and design of the study, critical revision.

IvPhD, Assistant Professor, Professional Master's degree, Program in Minimally Invasive Technology and Simulation in Health, UNICHRISTUS, Fortaleza-CE, Brazil. Conception and design of the study, interpretation and analysis of data, critical revision.

${ }^{V} \mathrm{MD}$, Holy House of Mercy of Fortaleza, Fortaleza-CE, Brazil. Conception and design of the study, technical procedures, interpretation and analysis of data, critical revision, final approval.

\section{Abstract}

Purpose: To develop a model and curriculum for simulated training of an effective and well accepted laparoscopic vesicourethral anastomosis (VUA).

Methods: Experimental longitudinal study of quantitative character. The sample consisted of 12 general surgery residents and 6 urology residents (R3). The training consisted of making twelve VUAs on synthetic organs. The training was divided into four sessions and accompanied by an instructor who performed positive feedback. The evaluation of the anastomoses considered the time and the analysis of the operative technique through the global evaluation scale Objective Structured Assessment of Technical Skills (OSATS).

Results: Residents showed a reduction in operative time and evolution in the surgical technique statistically significant $(p<0.01)$. The best-rated items were the facilitator positive feedback and the fact that the training was carried out at the teaching hospital premises.

Conclusions: The proposed training model was well accepted and proved to be effective in reducing operative time and improving laparoscopic skills. The training should be fractionated ( 4 sessions in 3 weeks), repetitive (12 anastomoses) and have positive feedback.

Key words: Education, Medical. Anastomosis, Surgical. Laparoscopy. Suture Techniques. Urologic Surgical Procedures. 


\section{Introduction}

The teaching of laparoscopic skills is a challenge in urology medical residency programs. Urological procedures performed by laparoscopy require skills other than open surgery and learning can increase surgical time and patient morbidity ${ }^{1}$. Because of the long learning curve, residents should acquire laparoscopic skills before performing procedures in the surgical center ${ }^{2}$.

The main limitations of most laparoscopic procedures are related to reconstructive maneuvers involving the use of differentiated skills and advanced endosuture techniques ${ }^{3}$. The most challenging part of laparoscopic radical prostatectomy (LRP) is vesicourethral anastomosis (VUA) and training in simulators may contribute to the facilitation of learning of this surgical time ${ }^{4}$.

Previous experience in laparoscopy is not necessary to acquire endosuture skills ${ }^{5}$ that can be acquired with extensive training outside the operating room ${ }^{5,6}$. Thus, many residency programs have included this practice as an essential activity in their curricula ${ }^{6}$. The aim of this research is to develop a model and curriculum for simulated training of a laparoscopic VUA that is effective and well accepted.

\section{Methods}

This longitudinal experimental study and of a quantitative character was approved by the Research Ethics Committee of Centro Universitário Christus (number 1801046) and Brazil platform system (Approval with CAAE number 60121916.0.0000.5049). This study respects the ethical precepts of human research and presents no possibility of damage to the physical, biological, psychic, moral, intellectual, social, cultural or spiritual dimension of the human being, at any stage of research or as a result of it. All participants signed the Term of Free and Cleared Up Consent.

The research was carried out in the Laboratory of Surgical Skills of Instituto Dr. José Frota, located in the city of Fortaleza-CE, Brazil. Participants in the survey were general surgery residents who were enrolled in the first ( $R 1, n=6)$ and second year residency ( $R 2$, $n=6)$ and third year urology residents (R5, $n$ $=6$ ). All residents of General Surgery (R1 and R2) came from the general surgery service of the Instituto Dr. José Frota. Urology Residents came from several hospitals, two from the General Hospital of Fortaleza, one from the Walter Cantídio University Hospital and two from the House of Mercy of Fortaleza.

The simulator used was the EndosSuture Training Box (ESTB). In order to perform the VUA, tweezers usually selected in laparoscopy were used: needle-holder, auxiliary needleholder, Maryland and laparoscopic scissors were used.

The VUA occurred between a synthetic urethra and bladder neck that were made with a polymer called elastomer. The thickness of the bladder wall was $3 \mathrm{~mm}$ and the diameter of the bladder neck $12 \mathrm{~mm}$. The urethra had a tubular shape having an internal diameter of $6 \mathrm{~mm}$ and a wall thickness of $5.5 \mathrm{~mm}$ (RS Medical Solutions). The urethra was attached to a rigid part composed of $150 \times 50 \times 17 \mathrm{~mm}$ of Vinylesiliconized Ethylene Acetate that simulated the human pelvis and was adhered to a plate of $160 \times 160 \times 10 \mathrm{~mm}$ (composed by wood, screws, carpet and stainless steel) with a 30 degree elevation relative to the surface. The bladder was located on the underside of the plaque and fit the urethra symmetrically at the end of the anastomosis. The bladder contained 4 holes that simulated the bladder neck and could be easily replaced as wear of the material during training occurred. The tubular structure used to represent the urethra could be cut into its distal portion as 
the material was worn out and thus renew the urethral stump to a new anastomosis. A 10fold Nelaton ${ }^{\circledR}$ urethral catheter was used to simulate the Foley catheter that is used during the anastomosis in real patients (Figure 1).

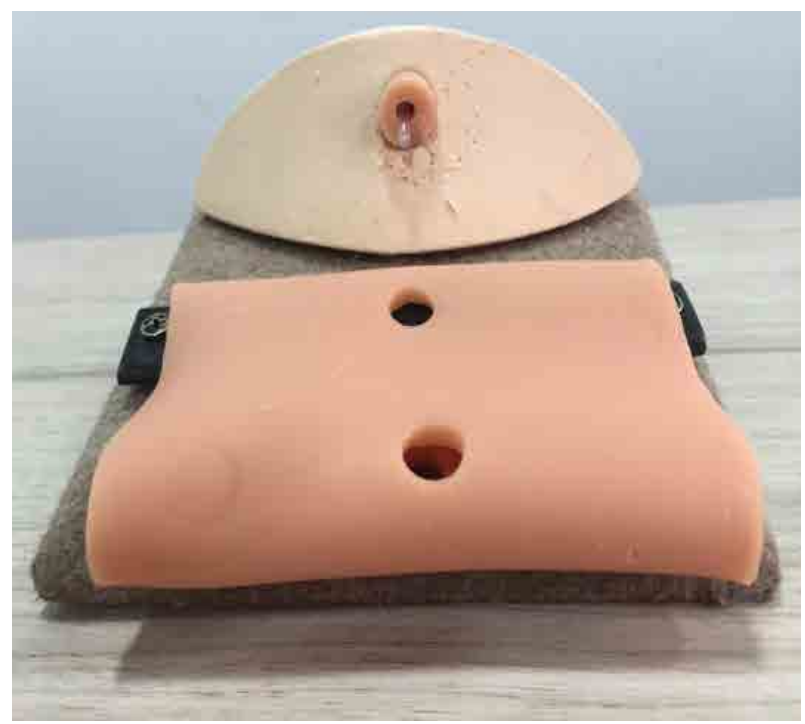

Figure 1 - Previous view of the synthetic urethral and bladder neck for VUA.

The density of the material used was improved so as to achieve resistance, resilience and thickness resembling the tissue of the bladder and the human urethra. The conformation and position of the synthetic organs attempted to reproduce the human anatomy. To perform the anastomosis, a Nylon 2.0 string with $1 / 2$ circle needle of $25 \mathrm{~mm}$ by TECHNOFIO ${ }^{\circ}$ brand was used. The string choice took into account its cost, availability and usability.

\section{Surgical procedure}

A first theoretical session with instructive video involving the proposed technique was carried out. The surgical team was composed of two residents and had as their criterion of choice their convenience. The team positioning was defined so that everyone would use both hands and, therefore, could interact during the procedure. The main surgeon positioned himself in front of the simulator and used 2 portals: one to the right and one to the left of the portal where the camera was placed. The assistant surgeon positioned himself to the right of the simulator and drove the camera, located in the central portion of the simulator, and assisted the primary surgeon through a fourth portal in front of him (Figure 2).

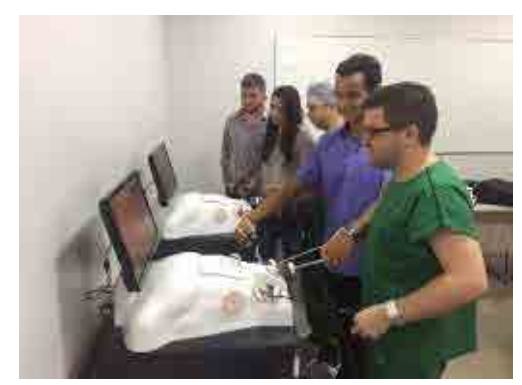

Figure 2 - Positioning of the surgical team.

The VUA was made by means of a continuous circular suture following the counterclockwise direction in the bladder and clockwise in the urethra and it was composed of 7 suture insertion sites in each structure: $3 \mathrm{~h}$, $1 \mathrm{~h}, 12 \mathrm{~h}, 11 \mathrm{~h}, 9 \mathrm{~h}, 7 \mathrm{~h}$ and $5 \mathrm{~h}$, the needle being positioned from the outside into the bladder and from the inside out into the urethra. After the passage of the 9-h point in the bladder the urethral catheter was inserted into the bladder neck. The procedure was closed with 4 adjusted nodes.

\section{Training curriculum}

The participants carried out the training by performing twelve manual anastomoses that were divided into four sessions of three anastomoses. The training had a 1-week interval and lasted approximately 2 hours, totalizing 8 hours of training in 3 weeks. 
During the follow-up of the procedure, the assistant surgeon provided positivefeedback by encouraging and guiding participants. This feedback was intended to expand, refine, and build new skills. It established goals and objectives to be achieved.

\section{Evaluation of anastomoses}

The judgment of the anastomoses made occurred in two stages. At the first moment, time was checked to carry out the proposed task. Time marking was initiated when the participant placed the tweezers in the simulator and finished when the suture was removed. The third, sixth, ninth and twelfth anastomosis were filmed without identification of the residents. In the second moment, a blind surgeon analyzed the videos of the proposed procedure in order to evaluate the technical skill in the making of anastomoses through the global evaluation scale Objective Structured Assessment of Technical Skills (OSATS) ${ }^{7,8}$.

\section{Questionnaires}

Before starting the training, residents answered a questionnaire about epidemiological variables (age, gender, dominant hand), previous experience in laparoscopic surgery and use of abdominal cavity simulators in laparoscopy teaching. After the experiment completion, each resident answered a questionnaire that assessed VUA training through scored answers on a 5-point Likert scale.

\section{Pilot project}

Through a pilot project, six urologists with experience in more than twenty laparoscopic VUAs were selected from real patients. They performed 3 anastomoses in a single moment. The average of the times obtained in the VUA was considered the optimal time to be reached at the end of the training.

\section{Statistical analysis}

The categorical quantitative results were presented as percentages and counts, and the numerical results were measured as central trend measures. Normality tests were performed for numerical variables. Depending on the normality of the variables, ANOVA or Mann-Whitney tests were performed, as appropriate. For categorical variables, the chisquare test was used. Simple linear regression and multiple analyzes were performed to verify the statistical significance of the correlations. Comparisons with $p$ value up to 0.05 were considered significant. The data were tabulated and analyzed by the SPSS software (Statistical Package for the Social Sciences), v23, SPSS, Inc. for the analysis and evaluation of the collected data.

\section{- Results}

The participants age average was 29.1 \pm 4.4 years. The male gender was predominant $(94.4 \%)$ and the right hand was dominant in $94.4 \%$ of the residents. Regarding the previous experience in laparoscopy, the most performed procedures were cholecystectomy (100\%) and appendectomy (R1 and R2: 50\%, R5: 100\%). General surgery residents had no experience with other laparoscopic procedures. In the group of residents of Urology (R5) there was a more varied previous experience, since $100 \%$ had undergone nephrectomy and prostatectomy, $66.7 \%$ pyeloplasty and oophorectomy and $16.7 \%$ hernioplasty, fundoplication, rectosigmoidectomy and gastrojejunoanastomosis. A urology resident stated that he performed laparoscopic anastomoses frequently. Regarding previous training in laparoscopic simulators, fifteen residents had performed some type of training before starting the study and the simulator that had been most used was the ESTB (72.2\%). 
All the residents were interested in having access to the simulators in order to improve their laparoscopic skills and they considered as positive the training in simulators before the surgical learning in humans. When questioned about the ideal time to begin laparoscopic surgery training in simulators, $88.9 \%$ of residents responded that it would be during General Surgery residency. Regarding periodicity, almost $90 \%$ answered that the training should be performed monthly. All residents believe that including training of surgeons in simulators can reduce complications in laparoscopic surgery. They, too, agree that the repetition of a surgical procedure in simulator is able to reduce the operative time and that the skills learned can be transferred to the operating room. Regarding the fact that the training was carried out in a teaching hospital, all residents considered it excellent.

Table 1 shows the average time that each group of residents needed to make the VUA. It is also possible to identify the average time of each training session. Therefore, the average time of the first anastomosis of all the residents (22 minutes) was well above the average time of the best expert surgeon anastomosis, which was $8.3 \pm 0.8$ minutes. The $p$-value showed a statistically significant difference $(p<0.001)$.

Table 1 - Distribution of the average times for the VUA creation of the residents.

\begin{tabular}{|c|c|c|c|}
\hline \multirow{2}{*}{ Anastomosis } & \multicolumn{3}{|c|}{ Time (minutes) } \\
\hline & R1 & $\mathbf{R 2}$ & R5 \\
\hline 1… & $35 \pm 13.2$ & $23.2 \pm 9.4$ & $23.2 \pm 8$ \\
\hline $2 \mathrm{a}$. & $26.9 \pm 8.5$ & $20.2 \pm 5.9$ & $17.2 \pm 4.5$ \\
\hline 3… & $22.2 \pm 5.6$ & $18.7 \pm 7.6$ & $15.5 \pm 6.4$ \\
\hline Average 1a Session & $28.2 \pm 8.6$ & $20.5 \pm 7.2$ & $18.3 \pm 5.6$ \\
\hline $4 \stackrel{a}{ }$. & $20.8 \pm 7$ & $17.5 \pm 4.7$ & $15.5 \pm 7$ \\
\hline 5 a. & $19.3 \pm 6.4$ & $15 \pm 2.9$ & $15 \pm 4.7$ \\
\hline 6a. & $17.3 \pm 4.7$ & $13.2 \pm 1.7$ & $13.2 \pm 3$ \\
\hline Average 2a Session & $19.2 \pm 4.7$ & $15.5 \pm 2.9$ & $14.5 \pm 4.8$ \\
\hline 7a. & $16.7 \pm 6.9$ & $15 \pm 3.6$ & $12.5 \pm 5.9$ \\
\hline 8… & $14.2 \pm 5.7$ & $12.5 \pm 2.1$ & $13.3 \pm 5$ \\
\hline 9a. & $16.3 \pm 6.5$ & $12.2 \pm 3.5$ & $11.8 \pm 2.9$ \\
\hline Average 3a Session & $15.7 \pm 5.9$ & $13.3 \pm 2.9$ & $12.5 \pm 4.4$ \\
\hline 10 a. & $15 \pm 6.9$ & $12.8 \pm 1$ & $11.5 \pm 5.1$ \\
\hline 11 a. & $13.7 \pm 4.1$ & $11.5 \pm 0.8$ & $11.3 \pm 4.3$ \\
\hline $12^{\mathrm{a}}$. & $14.2 \pm 6.9$ & $11 \pm 0.6$ & $10.7 \pm 3.7$ \\
\hline Average 4a Session & $14.3 \pm 5.7$ & $11.8 \pm 0.8$ & $11 \pm 4.2$ \\
\hline
\end{tabular}

Figure 3 shows that the average time of the anastomosis of the last session of the residents (12.3 \pm 3.5 minutes) was similar to the average time of the best anastomosis of the expert surgeons ( $8.3 \pm 0.8$ minutes). The $p$ value showed a statistically significant difference $(p=0.002)$. 


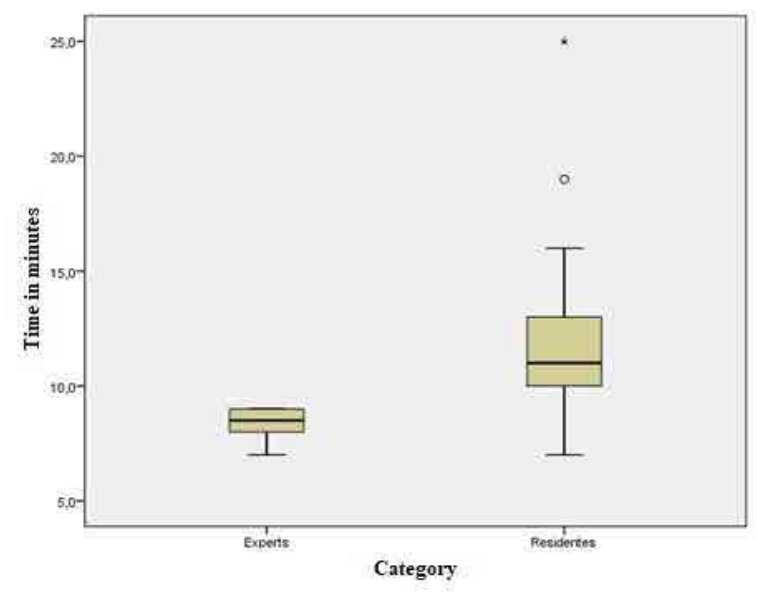

Figure 3 - Relationship between the times of the last anastomosis of the resident and the best anastomosis of the experts.

There was a statistically significant difference at the end of the training between the times of anastomosis found in the R1 and R2 groups when compared to the experts group. There was no statistically significant difference at the end of the training when the $\mathrm{R} 5$ group was compared to the group of experts $(p=0.615)$.

Figure 4 shows that the quality of the anastomosis, measured through the OSATS score, improved during the training with a statistically significant difference ( $p<0.01)$.
The $r$ of 0,657 represents a high correlation between the improvement in the OSATS scale score and the number of anastomoses made.

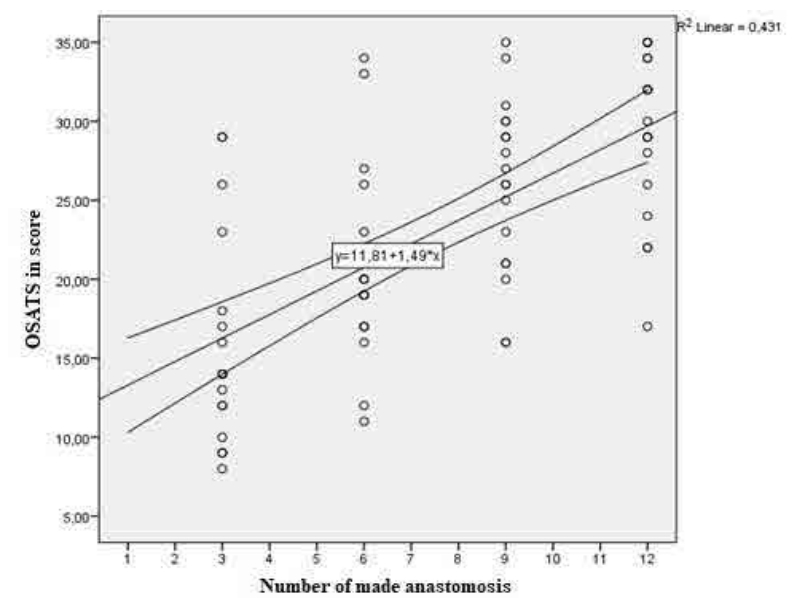

Figure 4 - Relationship between the number of anastomoses performed and the score on the OSATS scale.

When analyzing the groups, it was observed that in the first year residents group there was an initial score on the OSATS scale that was much lower than that found in the other groups, but from the third session on this score equalized or became very close to the other groups. Table 2 shows the evaluation of the residents participating in the VUA training in relation to it.

Table 2 - VUA training model evaluation.

\begin{tabular}{lccccc}
\multicolumn{1}{c}{ Variables } & Insufficient & Regular & Good & Excellent & Great \\
\hline Training to be done at the teaching hospital premises & - & $1(5.6)$ & $1(5.6)$ & $1(5.6)$ & $15(83.3)$ \\
Use of ESTB in the manufacture of a laparoscopic & - & - & - & $7(38.9)$ & $11(61.1)$ \\
anastomosis & - & - & - & $7(38.9)$ & $11(61.1)$ \\
Synthetic organs used in training & - & - & $1(5.6)$ & $8(44.4)$ & $9(50)$ \\
Tweezers used during training & - & - & - & $4(22.2)$ & $14(77.8)$ \\
Number of training sessions & - & - & $2(11.1)$ & $7(38.9)$ & $9(50.0)$ \\
Duration of each training (2 hours) & - & - & - & $4(22.2)$ & $14(77.8)$ \\
Duration of all training (4 weeks) & - & - & $2(11.1)$ & $5(27.8)$ & $11(61.1)$ \\
Interval between each training session (1 week) & - & $1(5.6)$ & - & $6(33.3)$ & $11(61.1)$ \\
Number of anastomoses performed during training & - & - & - & $2(11.1)$ & $16(88.9)$ \\
(12) & - & - & &
\end{tabular}




\section{- Discussion}

VUA is a challenging moment and timeconsuming for PRL. Regardless of the technique used for anastomosis, the restoration of continuity of the urinary tract should be safe, effective and easy to be learnt by the surgeon, and should provide a rapid and complete return of urinary continence ${ }^{9}$. Lorenzo et al. ${ }^{10}$ emphasize the importance of learning and practicing advanced laparoscopic skills in the skills laboratory before the operating room, aiming to make the most of opportunities with real patients. Training improves laparoscopic suturing skills, helping to reduce the learning curve $^{11}$.

Animal models are the closest to operating a living patient, since they can effectively simulate bleeding and complications. However, they are expensive and are associated with infectious, moral, and ethical concerns ${ }^{12}$. Due to the scarcity of corpses and ethical and moral questions around their use, resources should not be directed to this model of simulation ${ }^{13}$. Therefore, the training of anastomoses in synthetic organs accommodated within black box simulators appears as an excellent option in continuing education in advanced laparoscopic surgery ${ }^{14}$.

Barreira et al. ${ }^{15}$ showed that residents wishing to acquire the ability to make a laparoscopic anastomosis need to train in a black box simulator using a structured curriculum. It is necessary to prepare ten anastomoses as the main surgeon and ten as an assistant surgeon to acquire a level of proficiency similar to skilled surgeons. The procedures should be distributed in five sessions, with approximate interval of one week and duration of six weeks. The training should be mandatory, accessible and accompanied by an experienced surgeon who provides individualized feedback. However, in a training program it is more important to define a skill point to be achieved rather than the number of hours ${ }^{16}$ and the learning success is more related to individual efforts than to a set number of sessions ${ }^{17}$.

The concern with the surgical development after the residence has been causing discussions about the curriculum of surgical training ${ }^{18,19}$. A study carried out with 186 surgeons showed that there is a need to create a curriculum for advanced laparoscopic skills simulated training. Respondents felt that the curriculum should depend on the practitioners' viability and ability to repeat the exercises as often as needed ${ }^{20}$.

These are items needed to develop a simulated training curriculum for surgical procedures: using pre- and post-tests to assess knowledge; know the procedure that will be performed; establish a level of proficiency for each task based on the experts performance; provide feedback during training sessions to stimulate performance improvement; set a training schedule; create a specific evaluation tool for the exercise carried out; develop a module for teaching non-technical skills; and to validate a training model through continuous evaluations and the search for improvements ${ }^{21}$. According to Van Hove et al. ${ }^{22}$, the evaluation of surgical procedures by videos may be a means of evaluating individuals with different levels of experience, but there is no evidence that it is possible to identify subtle differences among surgeons.

This work evaluated several aspects of the VUA, judging the acquisition of laparoscopic skills by heterogeneous groups of residents submitted to the same training curriculum. In addition to the decreasing of time in the anastomosis preparation, the improvement in the learning of laparoscopic skills was evidenced. It was observed that residents with different degrees of experience were able to achieve similar results at the end 
of the training and also close operative time of the experts. The evaluation of the training was positive and the items with the best scores were facilitated by the fact that the training was carried out at the teaching hospital premises.

The time curve to perform certain surgical exercises by laparoscopy is a parameter used as a measure of acquisition of laparoscopic skills in several studies ${ }^{15,23,24}$. The OSATS scale is applied to any assessment of surgical skills and assesses knowledge, manipulation skill, and action record. It consists of seven assessment items on a 5-point Likert scale. The minimum score of each participant may be 7 points and the maximum of 35 points, having to reach 21 points or more to be considered competent in an individual task. This scale has shown to be a reliable and valid method for testing surgical skills in residents and was one of the first methods designed for the evaluation of competences $^{8}$.

The model presented comes with the proposal to use synthetic organs that come to mimic human tissues in appearance, consistency and format. Furthermore, there is still a proposal to develop these models at an affordable cost so that they can be incorporated into medical residency programs and urological surgeon training programs that aim to improve the technique.

\section{- Conclusions}

The laparoscopic vesicourethral anastomosis training model, through the use of synthetic organs, was well accepted and proved effectiveness in reducing operative time and improving laparoscopic skills. The training should be fractional (4 sessions in 3 weeks), repetitive (12 anastomoses), short duration ( 2 hours per week), have positive feedback, easy access environment and good quality materials.

\section{References}

1. Torricelli FC, Guglielmetti G, Duarte RJ, Srougi M. Laparoscopic skill laboratory in urological surgery: tools and methods for resident training. Int Braz J Urol. 2011 Feb;37(1):108-12. doi: 10.1590/S167755382011000100014.

2. Yamanaka H, Makiyama $K$, Tatenuma T, Sakata R, Sano F, Kubota Y. Preparation for pyeloplasty for ureteropelvic junction obstruction using a patient-specific laparoscopic simulator: a case report. J Med Case Rep. 2012 Oct;6(338):1-4. doi: 10.1186/1752-1947-6-338.

3. Pérez-Duarte F, Fernández-Tomé F, DíazGuemes I, Enciso S, Matos-Azevedo AM, Sánchez-Hurtado MA, Hernández L, Sánchez-Margallo FM. Development and initial assessment of a training program for laparoscopic radical prostatectomy. First module: the urethrovesical anastomosis. J Endourol. 2014 Jul;28(7):854-60. doi: 10.1089/end.2014.0050.

4. Aykan S, Singhal $P$, Nguyen DP, Yigit A, Tuken M, Yakut E, Colakerol A, Sulejman S, Semercioz A. Perioperative, pathologic, and early continence outcomes comparing three-dimensional and two-dimensional display systems for laparoscopic radical prostatectomy - A retrospective, single-surgeon study. J Endourol. 2014 May;28(5):539-43. doi:0.1089/ end.2013.0630.

5. Brown DC, Miskovic D, Tang B, Hanna GB. Impact of established skills in open surgery on the proficiency gain process for laparoscopic surgery. Surg Endosc. 2010 June;24(6):1420-6. doi: 10.1007/s00464009-0792-9.

6. Nguyen PH, Acker CE, Heniford BT, Stefanidis $D$. What is the cost associated with the implementation of the FLS program into a general surgery residency? Surg Endosc. 2010 Dec;24(12):3216-20. doi: 10.1007/ s00464-010-1082-2.

7. Denadai R, Saad-Hossne R, Todelo AP, Kirylko L, Souto LR. Low-fidelity bench models for basic surgical skills training during undergraduate medical education. Rev Col Bras Cir. 2014 Mar-Apr;41(2):1-9. doi: 10.1590/S0100-69912014000200012. 
8. Martin JA, Regehr G, Reznick R, MacRae $\mathrm{H}$, Murnaghan J, Hutchison C, Brown M. Objective structured assessment of technical skill (OSATS) for surgical residents. Br J Surg. 1997 Feb;84(2):273-8. doi: 10.1046/j.13652168.1997.02502.x.

9. Golabek T, Wiatr T, Przydacz M, Bukowczan J, Dudek P, Sobczynski R, Golabek K, Chłosta PL. Optimizing the formation of vesicourethral anastomosis and reduction of procedure time. A two-year experience with a modified technique for endoscopic running vesicourethral anastomosis. Cent European J Urol. 2015 Sep;68(3):296-301. doi: 10.5173/ceju.2015.617.

10.Lorenzon L, La Torre M, Mercantini P, Ziparo $\mathrm{V}$. The strange case of $\mathrm{Dr}$ Jekyll and $\mathrm{Mr}$ Hyde (about surgery and basic research). A perspective for a new approach for pursuing an academic career (also in Italy). Int J Surg. 2012 Apr;10(5):275-6. doi: 10.1016/j. ijsu.2012.03.016.

11.Bansal VK, Tamang T, Misra MC, Prakash P, Rajan K, Bhattacharjee HK, Kumar S, Goswami A. Laparoscopic suturing skills acquisition: a comparison between laparoscopy-exposed and laparoscopynaive surgeons. JSLS. 2012;16(4):623-31. doi: $10.4293 / 108680812 \times 13462882737375$.

12. Hammoud MM, Nuthalapaty FS, Goepfert $A R$, Casey PM, Emmons S, Espey EL, Kaczmarczyk JM, Katz NT, Neutens JJ, Peskin EG. To the point: medical education review of the role of simulators in surgical training. Am J Obstet Gynecol. 2008 Oct;199(4):33843. doi: 10.1016/j.ajog.2008.05.002.

13.Vallas $\mathrm{CH}$, Alexiou K, Alexandrou A, Economou N. Different forms of laparoscopic training: review and comparison. Hellenic J Surg. 2015 Jan;86(6):337-46. doi: 10.1007/ s13126-014-0157-2.

14. Barreira MA, Siveira DG, Rocha HA, MouraJunior LG, Mesquita CJ, Borges GC. Model for simulated training of laparoscopic gastroenterostomy. Acta Cir Bras 2017 Jan:32(1): 81-9. doi: 10.1590/s0102865020170110.

15. Barreira MA, Rocha HA, Mesquita CJ, Borges GC. Desenvolvimento de um currículo para treinamento simulado de uma anastomose laparoscópica. Rev Bras Educ Med. 2017 Mar;41(3): 424-
31. doi: 10.1590/1981-52712015v41n3 rb20160106.

16.Varas J, Mejía R, Riquelme A, Maluenda F, Buckel E, Salinas J, Martínez J, Aggarwal $R$, Jarufe N, Boza C. Significant transfer of surgical skills obtained with an advanced laparoscopic training program to a laparoscopic jejunojejunostomy in a live porcine model: feasibility of learning advanced laparoscopy in a general surgery residency. Surg Endosc. 2012 Dec;26(12):3486-94. doi: 10.1007/s00464012-2391-4.

17.Sweet RM, Mcdougall EM. Simulation and computer-animated devices: the new minimally invasive skills training paradigm. Urol Clin North Am. 2008 Aug;35(3):519-31. doi: 10.1016/j.ucl.2008.05.008.

18. Mattar SG, Alseidi AA, Jones DB, Jeyarajah DR, Swanstrom LL, Aye RW, Wexner SD, Martinez JM, Ross SB, Awad MM, Franklin ME, Arregui ME, Schirmer BD, Minter RM. General Surgery residency inadequately prepares trainees for fellowship: results of a survey of fellowship program directors. Ann Surg. 2013 Sep;258(3):440-9. doi: 10.1097/ SLA.0b013e3182a191ca.

19. Nakayama DK, Taylor SM. SESC Practice Committee survey: surgical practice in the duty-hour restriction era. Am Surg. 2013 Jul;79(7):711-5. PMID: 23816005.

20.Nepomnayshy D, Alseidi AA, Fitzgibbons SC, Stefanidis D. Identifying the need for and content of an advanced laparoscopic skills curriculum: results of a national survey. Am J Surg. 2016 Feb;211(2):421-5. doi: 10.1016/j. amjsurg.2015.10.009.

21.Zevin B, Levy JS, Satava RM, Grantcharov TP. A consensus-based framework for design, validation, and implementation of simulation-based training curricula in surgery. J Am Coll Surg. 2012 Oct; 215(4):5806. doi: 10.1016/j.jamcollsurg.2012.05.035.

22.Van Hove PD, Tuijthof GJ, Verdaasdonk EG, Stassen LP, Dankelman J. Objective assessment of technical surgical skills. $\mathrm{Br} \mathrm{J}$ Surg. 2010 Jul;97(7):972-87. doi: 10.1002/ bjs.7115.

23. Ferreira Filho F, Moura Júnior LG, Rocha HA, Rocha SG, Ferreira LF, Ferreira AF. Abdominal cavity simulator for skill progression in videolaparoscopic sutures in Brazil. Acta Cir 
Bras. 2018 Jan;33(1):75-85. doi: 10.1590/ s0102-865020180010000008.

24.Moura Júnior LG, Ramos $A$, Campos JM, Ferraz AA, Rocha HA, Costa GO. Modelo de avaliação de progressão de competência e habilidades em endossuturas por meio de treinamento em laboratório de habilidades cirúrgicas. Arq Bras Cir Dig.
2017 Set;30(4):256-9. doi: 10.1590/01026720201700040007.

\section{Acknowledgement}

To the engineer Regis Luiz Sabia de Moura.

\section{Correspondence:}

Eudes Fontenele Moraes Pinheiro

Rua Jurandyr Nunes, 1181

60833192 Fortaleza - CE Brasil

Tel.: (55 85)99154-0202

eudesurologia@icloud.com

Received: Apr 02, 2018

Review: June 06, 2018

Accepted: July 08, 2018
Conflict of interest: none

Financial source: none

${ }^{1}$ Research performed at Laboratory of Surgical Skills, Centro Universitário Christus University Center (UNICHRISTUS), Fortaleza-CE, Brazil. Part of Master degree thesis, Postgraduate Program in Minimally Invasive Technology and Health Simulation. Tutor: Rômulo Augusto da Silveira. 